\title{
A Nonantigenic Covalent Streptokinase-Polyethylene Glycol Complex with Plasminogen Activator Function
}

\author{
Shrin Rajagopalan, Steven L. Gonias, and Salvatore V. Pizzo \\ Departments of Pathology and Biochemistry, Duke University Medical Center, Durham, North Carolina 27710
}

Abstract

A series of new, covalent polyethylene glycol (PEG)-streptokinase adducts were synthesized and characterized. PEGs with average molecular weights of $2,000,4,000$, and 5,000 were activated with carbonyldiimidazole and coupled to the protein under standardized reaction conditions. Steady-state kinetic analysis demonstrated comparable $\boldsymbol{K}_{\mathrm{m}}$ values for the activation of plasminogen by streptokinase, PEG-2-streptokinase, and PEG-4-streptokinase. The $\boldsymbol{k}_{\mathrm{cat}}$ values were somewhat decreased when PEG-2 or PEG-4 was coupled to the streptokinase. Activation by the PEG-5 adduct did not follow MichaelisMenten kinetics under the conditions employed in this study. Plasmin activity obtained by incubating streptokinase derivatives with plasminogen also was studied as a function of time with each of the PEG-streptokinase derivatives. By this assay, incubations containing PEG-5-streptokinase and unmodified streptokinase demonstrated comparable activity while reaction mixtures containing PEG-2-streptokinase and PEG-4-streptokinase were slightly more active. Streptokinase incubated with plasminogen at a 1:1 molar ratio was extensively degraded after $30 \mathrm{~min}$ whereas PEG-2-streptokinase was resistant to plasmin cleavage. The derivatized proteins were radioiodinated and incubated in plastic microtiter plates that were coated with an immunoglobulin fraction containing antibodies to streptokinase. Binding of the PEG-streptokinase adducts was decreased by $>95 \%$ compared with unmodified streptokinase. Plasminogen activator complexes were formed by reacting the streptokinases with human plasminogen in vitro and the clearance studied in mice. Radioiodinated plasmin in complex with the PEG-streptokinase adducts cleared at a slower rate than did plasmin complexed with unmodified streptokinase. Catabolism of the protease still occurred by a mechanism that involved reaction with $\alpha_{2}$-macroglobulin as has been described for nonderivatized streptokinase-plasminogen complex (Gonias, S. L., M. Einarsson, and S. V. Pizzo, 1982, J. Clin. Invest., 70:412-423). When more extensive derivatization procedures were utilized, PEG-2-streptokinase preparations were obtained that further prolonged the clearance of complexed ${ }^{125} \mathrm{I}$-plasmin; however, these adducts did not uniformly retain comparable activity. It is suggested that PEG-streptokinase complexes with greatly reduced antigenicity may be useful in the treatment of thrombotic disorders.

Address reprint requests to Dr. Pizzo.

Received for publication 30 April 1984 and in revised form 19 October 1984.

J. Clin. Invest.

(C) The American Society for Clinical Investigation, Inc. 0021-9738/85/02/0413/07 \$1.00

Volume 75, February 1985, 413-419

\section{Introduction}

Streptokinase is a bacterial protein that forms, with human plasminogen, a noncovalent, one:one stoichiometric complex that functions as a plasminogen activator $(1,2)$. The association of streptokinase with plasminogen is rapid, and the complex does not dissociate under neutral, nondenaturing conditions $(3,4)$. Streptokinase is used to treat deep vein thrombosis $(5)$ and myocardial infarction (6). The amount of streptokinase required to achieve and maintain therapeutic levels is significantly affected by reactions of the plasminogen activator with plasma proteins. The streptokinase-plasmin complex is rapidly catabolized by the facilitated transfer of the plasmin to $\alpha_{2-}$ macroglobulin $\left(\alpha_{2} \mathrm{M}\right)^{1}$ in mice, and it has been suggested that the same reaction occurs in humans (7). The $\alpha_{2} \mathrm{M}$-plasmin complex is cleared from the circulation via specific $\alpha_{2} \mathrm{M}$ protease receptors in the liver (7). Streptokinase released from the complex also clears in the liver and may exist in a degraded form that clears more rapidly than native streptokinase (8).

Immunoglobulins may neutralize intravenously administered streptokinase. High titers of antibody are present before therapy in some patients or may appear within 2 wk after an initial treatment, complicating long-term therapy (9). Koide et al. (10) substantially decreased the reactivity of streptokinase with antibody (antigenicity) by conjugating the protein to polyethylene glycol (PEG; $M_{\mathrm{r}} 5,000$ ), a nonantigenic polymer. The PEG was first activated by incubation with cyanuric chloride to form 2-O-methoxypolyethylene glycol-4,6-dichloro$S$-triazene. Streptokinase was then modified by incubating the protein with the activated PEG, which binds to free amino groups. The PEG-derivatized streptokinase was not antigenic; however, the adduct lost $67-99 \%$ of its original plasminogen activating activity.

Recently, this laboratory described a novel method of PEG activation, utilizing 1,1'-carbonyldiimidazole to form an imidazole carbamate derivative of the polymer (11). This activated PEG couples to lysine residues in proteins. Proteins derivatized with 1,1'-carbonyldiimadazole-activated PEG demonstrate significantly lengthened plasma half-lives and only minimally decreased activity (11). A modified streptokinase-plasmin(ogen) activator complex with these properties might have therapeutic advantages.

In the present study, streptokinase was derivatized with PEG $\left(M_{\mathrm{r}}=2,000,4,000,5,000\right)$ and compared with the unmodified protein. Chromogenic substrate assays demonstrated that PEG-streptokinase complexes can be synthesized without substantial loss of activity. Steady-state kinetic parameters were measured for each derivative. An in vitro radioligand-binding

1. Abbreviations used in this paper: $\alpha_{2} \mathbf{M}, \alpha_{2}$-macroglobulin; PEG, polyethylene glycol. 
assay showed that the derivatized protein reacted poorly with human antibodies directed against streptokinase. The clearance rates of plasmin and streptokinase from preformed activator complexes containing PEG-modified protein were also studied. A mouse model is particularly useful for these clearance experiments because mouse plasminogen does not react with streptokinase, although mouse and human $\alpha_{2} \mathrm{M}$ react with activator complex formed with human plasmin(ogen) similarly (7). Thus, it is possible to study the clearance of streptokinase and streptokinase-plasmin(ogen) complex in the same animal model.

\section{Methods}

Reagents. Bovine serum albumin and 1,1'-carbonyldiimidazole were obtained from Sigma Chemical Co., St. Louis, MO; $\mathrm{Na}^{125}$ I from New England Nuclear, Boston, MA; lactoperoxidase coupled to Sepharose from P-L Biochemicals, Inc., Milwaukee, WI; and electrophoresis reagents from Bio-Rad Laboratories, Richmond, CA. The plasmin substrate, H-D-Valyl-L-Leucyl-L-Lysine-p-nitroanilide-2HCl (S-2251), was purchased from the Helena Laboratories, Beaumont, TX; PEG-4 (Carbowax 4000) was purchased from Fisher Scientific Co., Raleigh, NC; PEG-2 and PEG-5 from Polysciences, Inc., Warrington, PA. Spectrapor dialysis tubing (Spectrum Medical, Inc., Los Angeles, CA) was obtained from Fisher Scientific Co. All other reagents were of the best grade commercially available.

Proteins. Plasminogen was prepared from human plasma by affinity chromatography on lysine-Sepharose as described by Deutsch and Mertz (12) and modified by Brockway and Castellino (13) to include gradient elution. Streptokinase was purified from Kabikinase (Kabi Co., Stockholm, Sweden) by the method of Castellino et al. (14). Human $\alpha_{2} M$ and $\alpha_{2} M$-methylamine were prepared as described previously $(7,15)$. The plasminogen-activator complex was prepared by incubating plasminogen with streptokinase or PEG-streptokinase in a 1:1.2 molar ratio for $15 \mathrm{~min}$ at $37^{\circ} \mathrm{C}$.

PEG activation. PEG was activated by the method of Beauchamp et al. (11). Polyethylene glycol $\left(M_{\mathrm{r}} 2,000\right.$, PEG-2; 4,000, PEG-4; 5,000, PEG-5) was dissolved in dioxane at $37^{\circ} \mathrm{C}$ at a concentration of 50 mM. 1,1'-carbonyldiimidazole was added to a final concentration of $0.5 \mathrm{M}$ and the solution was incubated at $37^{\circ} \mathrm{C}$ for $2 \mathrm{~h}$ with stirring. The solutions then were dialyzed extensively against $\mathrm{H}_{2} \mathrm{O}$ using Spectrapor membranes with $M_{\mathrm{r}}$ inclusion limits of 1,000 for PEG-2, 2,000 for PEG-4, and 3,500 for PEG-5. Activated PEG preparations were lyophilized and stored desiccated at $4^{\circ} \mathrm{C}$.

PEG-streptokinase coupling. Activated PEG was reacted with streptokinase $(1 \mu \mathrm{M})$ in $10 \mathrm{mM}$ sodium borate buffer, $\mathrm{pH} 8.5$, at $4^{\circ} \mathrm{C}$ for $72 \mathrm{~h}$ with $40 \mathrm{mM}$ of activated PEG (protocol A). Activated forms of PEG spontaneously hydrolyze in water and this may affect the efficiency of protein coupling (11). To determine whether more extensive derivatization would cause protein activity loss, protocol A for reacting streptokinase was modified by incubation of streptokinase with $80 \mathrm{mM}$ of activated PEG under the above conditions (protocol B). In one experiment, the streptokinase was reacted with $40 \mathrm{mM}$ of PEG for 48 $\mathrm{h}$ and then $80 \mathrm{mM}$ of PEG for an additional $48 \mathrm{~h}$ (protocol C). As a control, streptokinase was also incubated with nonactivated PEG under identical conditions.

Protein concentrations. Concentrations of purified protein preparations were determined by utilizing the following extinction coefficients (at $\lambda=280 \mathrm{~nm}$ ) and molecular weights: streptokinase, $A 1 \% / 1 \mathrm{~cm}$ $=7.5, M_{\mathrm{r}} 50,200(16) ;$ plasminogen, $A 1 \% / 1 \mathrm{~cm}=16.8, M_{\mathrm{r}} 92,000$ (17); $\alpha_{2} \mathrm{M}, A 1 \% / 1 \mathrm{~cm}=8.93, M_{\mathrm{r}} 718,000$ (18).

Protein radiolabeling. Proteins were radioiodinated by the solidstate lactoperoxidase method as previously described (19). Radioactivity was measured with a Scientific Products AW14-120 Gamma Counter (Scientific Products, Inc., Division of American Hospital Supply Corp., McGaw Park, IL).
Steady-state kinetics as determined by initial rate measurements. The kinetics of plasminogen activation by streptokinase-plasmin(ogen) and PEG-streptokinase-plasmin(ogen) were examined as described by Wohl et al. $(20,21)$. Studies were conducted at $37^{\circ} \mathrm{C}$ using the plasmin substrate S-2251. The substrate was dissolved in $50 \mathrm{mM}$ Tris- $\mathrm{HCl}, 100$ $\mathrm{mM} \mathrm{NaCl}, \mathrm{pH} 7.4$, at a final concentration of $5 \times 10^{-4} \mathrm{M}$. Plasminogen was present at final concentrations ranging from $1 \times 10^{-8} \mathrm{M}$ to 1.5 $\times 10^{-6} \mathrm{M}$. Streptokinase (final concentration, $2.5 \times 10^{-9} \mathrm{M}$ ) or PEGstreptokinase (final concentration, $5.0 \times 10^{-9} \mathrm{M}$ ) was added to initiate the reaction. The final sample volume was $1 \mathrm{ml}$. Substrate hydrolysis was monitored at $\lambda=\mathbf{4 0 5} \mathrm{nm}$ in a Gilford recording spectrophotometer (Gilford Instrument Laboratories, Inc., Oberlin, $\mathrm{OH}$ ) with thermostated cuvettes. Under the specified reaction conditions, only a small fraction of the plasminogen is activated so that pseudo-first-order kinetics apply and the reaction is described by the equation: $\Delta A_{405 \mathrm{~nm}}=a t+\frac{b}{2} t^{2}$. A plot of $\Delta A_{405 \mathrm{~nm}} / t$ versus $t$ is linear with a slope of $b / 2$. The constant $b$ is related to the initial velocity of plasmin formation $v$ by the following equation: $v=\frac{b\left(1+K_{\mathrm{E} / \mathrm{S}_{\mathrm{o}}}\right)}{\epsilon k_{\mathrm{E}}}$, where $K_{\mathrm{E}}$ is the apparent Michaelis constant for substrate hydrolysis by plasmin $\left(3 \times 10^{-9} \mathrm{M}\right), k_{\mathrm{E}}$ is the catalytic rate constant for substrate hydrolysis by plasmin $\left(1.35 \times 10^{3} \mathrm{M}\right.$ / $\mathrm{min} \cdot \mathrm{mol}$ plasmin), $\epsilon$ is the molar extinction coefficient of S-2251 (1 $\times 10^{4} \mathrm{M}^{-1} \cdot \mathrm{cm}^{-1}$ at $405 \mathrm{~nm}$ ), and $S_{0}$ is the concentration of S-2251 in the reaction mixture. Kinetic constants were calculated from initial rates by using the Lineweaver-Burk equation, where $K_{\mathrm{m}}$ is the apparent Michaelis constant for the substrate plasminogen and $k_{\text {cat }}$ is the catalytic rate constant of activation. In experiments with activators formed by derivatizing streptokinase by protocol $\mathrm{A}$, plasminogen concentrations ranged from 0.1 to $0.7 K_{\mathrm{m}}$ (PEG-2-streptokinase) and 0.4 to $4.0 K_{\mathrm{m}}$ (PEG-4-streptokinase). For activators that contained streptokinase derivatized by protocol $\mathrm{B}$, plasminogen concentrations ranged from 0.1 to $0.75 K_{\mathrm{m}}$ (PEG-2-streptokinase) and 0.9 to $3.3 K_{\mathrm{m}}$ (PEG-4-streptokinase). The activator species containing PEG-5-streptokinase did not follow Michaelis-Menten kinetics when the plasminogen concentration was varied between $1 \times 10^{-8} \mathrm{M}$ and $1.5 \times 10^{-6}$ M. All kinetic data were analyzed on a Hewlett-Packard $11 \mathrm{C}$ calculator (Hewlett-Packard Co., Palo Alto, CA) employing a linear regression program. The data when fitted to a straight line demonstrated $r^{2}$ values that were always $>0.90$ and usually $>0.99$.

Plasmin activity obtained by incubating the streptokinase derivatives with plasminogen as a function of time. Plasminogen, $2.2 \mu \mathrm{M}$, was incubated with streptokinase or PEG-streptokinase, $4.4 \mathrm{nM}$, in 20 $\mathrm{mM}$ sodium phosphate, $100 \mathrm{mM} \mathrm{NaCl}$, pH 7.4 (phosphate-buffered saline [PBS]) at $22^{\circ} \mathrm{C}($ final volume $=100 \mu \mathrm{l})$. At the specified time intervals, 3 or $10 \mu$ l of each activation mixture were added to $500 \mu l$ of substrate solution (210 $\mu \mathrm{M} \mathrm{S}-2251$ in PBS) and incubated at $37^{\circ} \mathrm{C}$ for $10 \mathrm{~min}$. The reaction was terminated by adding $50 \mu \mathrm{l}$ of a $50 \%$ solution of acetic acid. The absorbance was determined at $\lambda=405$ $\mathrm{nm}$. Controls were performed by adding either streptokinase, plasminogen, or PEG alone to substrate solution. In each control, hydrolysis of substrate was insignificant. All studies were performed at least in duplicate and the results were averaged.

SDS polyacrylamide gel electrophoresis of streptokinase-plasmin(ogen) complexes. Streptokinase or PEG-2-streptokinase were incubated at a 1:1 molar rates with plasminogen for $30 \mathrm{~min}$ at $37^{\circ} \mathrm{C}$. The resultant complexes were subjected to SDS-polyacrylamide gel electrophoresis and the gels scanned with a densitometer as previously described (22). Native streptokinase and PEG-2-streptokinase were subjected to electrophoresis for comparison.

Reaction of streptokinase preparations with human antistreptokinase antibodies (antigenicity assays). Sera from four patients with high titers of antistreptokinase antibodies were kindly provided by Dr. Victor Marder, University of Rochester, Rochester, NY. These sera were pooled and dialyzed against PBS. A modification of the procedure described by Polson et al. (23) was utilized to prepare an immunoglobulin-enriched fraction of the sera. PEG $\left(M_{\mathrm{r}} 6,000\right.$, nonactivated) was 
added to dialyzed serum at $22^{\circ} \mathrm{C}$ for $30 \mathrm{~min}$ at a final concentration of $7.5 \%$ (final volume, $14 \mathrm{ml}$ ). The precipitate was collected by centrifugation at $1,300 \mathrm{~g}$ for $20 \mathrm{~min}$ in an IEC Centra-7R centrifuge (International Equipment Co., Needham Heights, MA) and redissolved in $3 \mathrm{ml}$ of PBS. Residual cloudiness, probably consisting of lipoproteins, was removed by microfiltration through a regenerated cellulose filter (pore size $0.2 \mu \mathrm{m}$ ) in a spin dialysis unit (Bioanalytical Systems, Inc., West Lafayette, IN). PEG was removed by gel filtration on a Sepharose 4B-CL column $(2 \times 15 \mathrm{~cm}$; Pharmacia Fine Chemicals, Piscataway, NJ) equilibrated in PBS. Elution fractions were monitored at $\lambda=280$ $\mathrm{nm}$ and the first major protein peak retained for preparation of microtiter plates for radioligand-binding assays.

A volume of $0.2 \mathrm{ml}$ of the immunoglobulin-enriched fraction was added to each well of a 24-well Linbro microtiter plate and incubated for $3 \mathrm{~h}$ at $22^{\circ} \mathrm{C}$ without rocking. Each well was then washed three times with $1.0 \mathrm{ml}$ of PBS and then incubated with $0.5 \mathrm{ml}$ of a $10 \mathrm{mg} /$ $\mathrm{ml}$ albumin solution for $2 \mathrm{~h}$ at $22^{\circ} \mathrm{C}$ with rocking. This second incubation was utilized to saturate remaining protein-binding sites on the plastic. The wells were washed with PBS after aspiration of the albumin solution. Protein-binding experiments were performed with $0.3 \mathrm{ml}$ of ${ }^{125} \mathrm{I}$-streptokinase or PEG- ${ }^{125}$ I-streptokinase (protocol A) in PBS at $22^{\circ} \mathrm{C}$. In one experiment, ${ }^{125}$ I-streptokinase, $10 \mathrm{nM}$, was incubated at times between $15 \mathrm{~min}$ and $6 \mathrm{~h}$. In other experiments, the concentration of radioligand was varied and the time of incubation was $6 \mathrm{~h}$. Binding experiments were terminated by removing the radioligand solution and washing the wells three times with PBS. Protein bound to the wells was solubilized in $0.1 \mathrm{~N} \mathrm{NaOH}$ for $12 \mathrm{~h} .{ }^{125} \mathrm{I}$ streptokinase or ${ }^{125}$ I-PEG-streptokinase complex that was recovered with the bound protein was quantified in a gamma counter (American Scientific Products, model AW14120). Equivalent incubations were performed in microtiter wells coated with albumin but not immunoglobulin-enriched fraction. Specific binding of radioligand was calculated as the difference in total binding observed between wells prepared with and without the immunoglobulin-enriched fraction. All experiments were performed in duplicate and the results were averaged. Individual variation for each point was generally $<5 \%$.

Plasma elimination studies. Radiolabeled ligands were injected alone or in the presence of unlabeled proteins into the lateral tail veins of $\mathrm{CD}-1$ female mice. In most experiments, $1.0 \mu \mathrm{g}$ of ${ }^{125}$ I-labeled protein was injected. Blood samples of $25 \mu \mathrm{l}$ were obtained at various time intervals by puncture of the retroorbital venous plexus with heparinized capillary tubes. Previous studies with CD-1 female mice from the same supplier indicate that high titers of antistreptokinase antibodies are not present in the serum of these mice (7). Moreover, the variation in clearance behavior with streptokinase and each preparation of PEG-streptokinase tested in multiple mice obtained in different lots was generally $<5 \%$ at each time point. The radioactivity in each sample was measured in a gamma counter. Experiments were performed with and without trichloroacetic acid precipitation of sampled blood, yielding similar data. Non-TCA precipitable counts represented $<3 \%$ of the total counts at each time point studied. This procedure is described in detail elsewhere (7).

Organ distribution studies. Animals were injected with radiolabeled ligand and then killed by cervical dislocation. Major body organs including kidneys, liver, lungs, heart, spleen, and gut were recovered, and retained radioactivity was measured in a gamma counter.

\section{Results}

Steady-state kinetic parameters as determined by initial rate measurements. The kinetic parameters of activation of plasminogen by streptokinase-plasmin(ogen) and the different PEG-streptokinase-plasmin(ogen) complexes are shown in Table 1. The apparent $K_{\mathrm{m}}, k_{\text {cat }}$, and $k_{\text {cat }} / K_{\mathrm{m}}$ values for streptokinase are in reasonable agreement with previously published results $(20,21)$. The apparent $K_{\mathrm{m}}$ values ranged from $0.27 \mu \mathrm{M}$ for PEG-4-streptokinase (protocol B) to $1.93 \mu \mathrm{M}$ for PEG-2-
Table I. Steady-State Kinetic Parameters for Plasminogen Activation by Streptokinase-Plasmin(ogen) and PEG-Streptokinase-Plasmin(ogen) Activator Complexes

\begin{tabular}{|c|c|c|c|c|}
\hline Activator & PEG & $K_{\mathrm{m}}$ & $k_{\text {out }}$ & $k_{\mathrm{cow}} / K_{\mathrm{m}}$ \\
\hline & $m M^{*}$ & $\mu M$ & $\min ^{-1}$ & $\mu M^{-1} \cdot \min ^{-1}$ \\
\hline $\begin{array}{l}\text { Streptokinase- } \\
\text { plasmin(ogen) }\end{array}$ & - & 0.89 & 30.40 & 34.23 \\
\hline $\begin{array}{l}\text { PEG-2-streptokinase- } \\
\text { plasmin(ogen) }\end{array}$ & 40 & 1.41 & 11.40 & 8.09 \\
\hline $\begin{array}{l}\text { PEG-2-streptokinase- } \\
\text { plasmin(ogen) }\end{array}$ & 80 & 1.93 & 7.08 & 3.67 \\
\hline $\begin{array}{l}\text { PEG-4-streptokinase- } \\
\text { plasmin(ogen) }\end{array}$ & 40 & 0.27 & 1.16 & 4.36 \\
\hline $\begin{array}{l}\text { PEG-4-streptokinase- } \\
\text { plasmin(ogen) }\end{array}$ & 80 & 0.45 & 0.01 & $2.22 \times 10^{-2}$ \\
\hline
\end{tabular}

* Concentration of PEG utilized in coupling procedure.

streptokinase (protocol A). The catalytic rate constants ranged from $0.01 \mathrm{~min}^{-1}$ for PEG-4-streptokinase (protocol B) to 30.4 $\min ^{-1}$ for underivatized streptokinase. The apparent secondorder rate constant, $k_{\text {cat }} / K_{\mathrm{m}}$ was also greatest for native streptokinase $\left(34.2 \mu \mathrm{M}^{-1} \cdot \mathrm{min}^{-1}\right)$ and decreased to $2.2 \times 10^{-2}$ $\mu \mathrm{M}^{-1} \cdot \mathrm{min}^{-1}$ for PEG-4-streptokinase (protocol B). The PEG5-streptokinase derivatives did not follow Michaelis-Menten kinetics and, therefore, $k_{\text {cat }}$ and $K_{\mathrm{m}}$ values are not presented.

Plasmin activity obtained by incubating the streptokinase derivatives with plasminogen as a function of time. Previous studies suggest that streptokinase undergoes slight degradation when reacted with human plasmin for $2-5 \mathrm{~min}(8)$. When rabbit plasminogen is substituted for human plasminogen, streptokinase degradation is extensive with fragments observed of $M_{\mathrm{r}} \sim 40,000,36,000,31,000,26,000$, and 10,000 (24). Steady-state kinetic constants assess only the initial rates of plasminogen activation and would not detect changes in activator function resulting from streptokinase degradation. When PEG is coupled to proteins, derivatization occurs at lysine residues (11) potentially decreasing the rate of degradation of PEG-streptokinase in activator complex. We, therefore, studied plasmin activity obtained by incubation of the streptokinase derivatives with plasminogen as a function of time. In the first series of experiments, plasminogen was incubated with streptokinase or PEG-derivatized streptokinase (protocol A). Plasmin activity was then assayed with S-2251. Experimental conditions were designed so that the concentration of activator complex was too low to cause detectable substrate hydrolysis alone and, in control experiments, no hydrolysis was measured when the plasminogen was omitted from the incubation media. Fig. $1 A$ shows that the amount of plasmin activity observed was comparable when PEG-5-streptokinase and native streptokinase were studied. When the reaction mixture contained PEG-2 or PEG-4, significantly more activity was observed.

Streptokinase derivatized with PEG-2 by protocols A and $B$ possessed the best activator function based on steady-state kinetics studies. PEG-2-streptokinase prepared either by protocol A or B generated similar amounts of plasmin activity over an extended period of time (Fig. $1 B$ ). It was, therefore, decided to examine derivatives formed by incubating streptokinase with activated PEG- 2 for longer periods of time. Because 


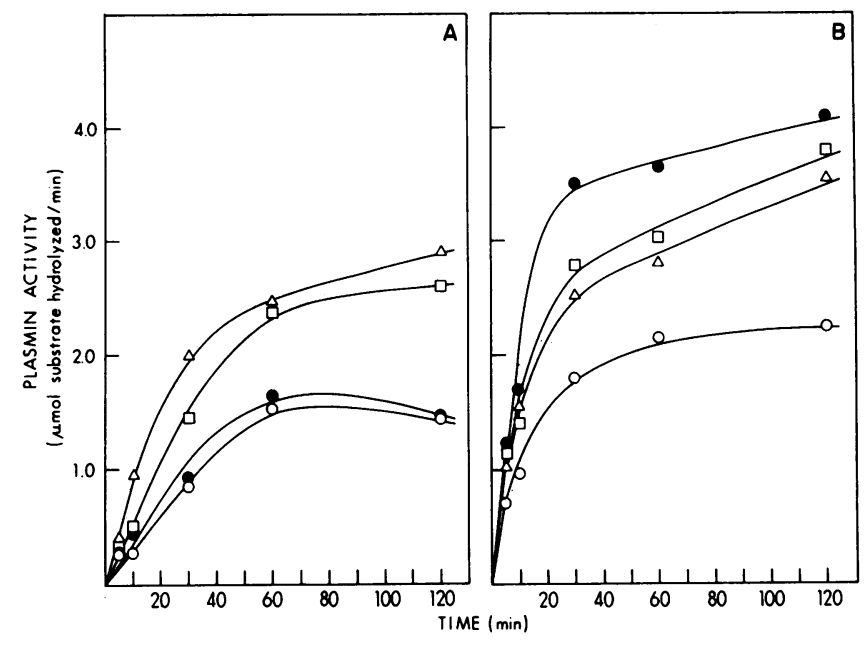

Figure 1. Plasmin activity obtained by incubating the streptokinase derivatives with plasminogen as a function of time. $(A)$ Plasminogen $(2.2 \mu \mathrm{M}$ in $20 \mathrm{mM} \mathrm{NaP}, 100 \mathrm{mM} \mathrm{NaCl}, \mathrm{pH} 7.4)$ was incubated with native streptokinase (๑), PEG-2-streptokinase ( $\square$ ), PEG-4-streptokinase $(\Delta)$, or PEG-5-streptokinase (0). These streptokinase adducts were prepared by derivatization in the presence of $40 \mathrm{mM}$ activated PEG (protocol A). The concentration of the streptokinase was 4.4 nM. At intervals, $3 \mu \mathrm{l}$ were removed and plasmin activity was determined as described in the text. $(B)$ Plasminogen $(2.2 \mu \mathrm{M})$ was incubated with $2.2 \mathrm{nM}$ streptokinase. The streptokinase was unmodified (๑), reacted with PEG-2 by protocol A (口), protocol B $(\Delta)$, or protocol C (O) as described in the text. At intervals, $10 \mu$ lof the plasminogen-streptokinase mixture was removed and plasmin activity was determined.

activated PEG hydrolyzes in an aqueous environment (11), the streptokinase was reacted with $40 \mathrm{mM}$ PEG-2 for $48 \mathrm{~h}$, and then the concentration of PEG was increased to $80 \mathrm{mM}$ for an additional $48 \mathrm{~h}$ (protocol $\mathrm{C}$ ). Significantly less plasmin activity was observed when streptokinase modified by protocol $\mathrm{C}$ was compared with the derivatives obtained by protocol $\mathrm{A}$ or $\mathbf{B}$.

Degradation of streptokinase-plasmin(ogen) complexes. The autodegradation of streptokinase-plasmin(ogen) complexes then was studied (Fig. 2). In that plasmin activity was nearly

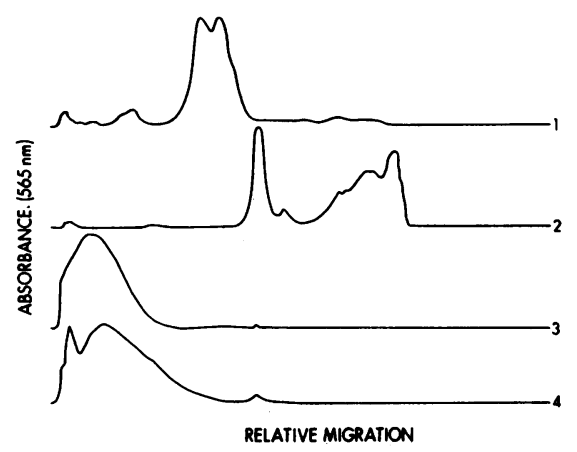

Figure 2. Degradation of streptokinase in activator complex. Streptokinase was incubated with plasminogen at a 1:1 molar ratio for 30 min and sodium dodecyl sulfate polyacrylamide gel electrophoresis performed and the gels scanned as previously described (22). Curve 1 is native streptokinase; curve 2 is native streptokinase incubated with human plasminogen. Curve 3 is PEG-2-streptokinase and curve 4 is PEG-2-streptokinase incubated with human plasminogen. maximal after $30 \mathrm{~min}$ incubation (Fig. 1), streptokinaseplasmin(ogen) complexes were prepared at a 1:1 molar ratio and incubated for $30 \mathrm{~min}$. This experiment demonstrated extensive degradation of the streptokinase to fragments of molecular weights comparable to those reported for streptokinase in complex with rabbit plasmin (24). Degradation was considerably more extensive than previously observed when streptokinase was reacted with human plasminogen (8). However, in these previous studies, the incubation time was only 2-5 min as contrasted to $30 \mathrm{~min}$. It is suggested that the plateau in plasmin activity (Fig. 1) is the result of digestion of the streptokinase in complex with plasmin.

Antigenicity of PEG-modified streptokinase. Radioiodinated streptokinase bound significantly to microtiter wells that were coated with the antistreptokinase immunoglobulin-enriched serum. Specific binding ranged between $60 \%$ and $80 \%$ of the total binding, and free and bound radioligand were in apparent equilibrium within $6 \mathrm{~h}$ (data not shown). This time period was chosen for comparison of the PEG-derivatized streptokinases with the unmodified protein. Each of the covalent PEGstreptokinase complexes studied demonstrated significantly reduced capacity to bind to the protein coated wells at all of the concentrations studied (Fig. 3). No attempt was made to determine whether this decreased binding represented thermodynamic and/or kinetic control of the reaction. Specific binding of PEG-streptokinase complexes ranged between $30 \%$ and $50 \%$ of the total binding. At a ligand concentration of 100 $\mathrm{nM}$, binding of the PEG derivatives was $\sim 5 \%$ that of native streptokinase. These data are consistent with a significantly reduced antigenicity of streptokinase after PEG modification.

Plasma elimination of native and PEG-modified streptokinase. The clearance of streptokinase derivatized with PEG-2, PEG-4, and PEG-5 (protocol A) was studied in mice. Control experiments were performed in which the streptokinase was incubated with nonactivated PEG before injection. The nonconjugated PEG had no effect on the clearance of streptokinase. Nonderivatized streptokinase cleared rapidly with $50 \%$ elimination occurring in $\sim 4 \mathrm{~min}$ (Fig. 4). An organ distribution study showed that the majority of the radioactivity localized in the liver and kidneys in $15 \mathrm{~min}$. All of the PEG-streptokinase derivatives cleared at a slower rate than the unmodified protein. The time required for the first $50 \%$ of each derivative to clear was $20 \mathrm{~min}, 15 \mathrm{~min}$, and $7 \mathrm{~min}$ for PEG-2-streptokinase, PEG-4-streptokinase, and PEG-5-streptokinase, respectively. Because mouse plasminogen does not form activator complex with streptokinase, these data do not reflect catabolic rates in man. However, these studies do demonstrate alteration of streptokinase properties after PEG coupling, as described with other proteins (11).

Plasma elimination of ${ }^{125}$ I-plasmin complexed with modified and unmodified streptokinase. Intravenously administered

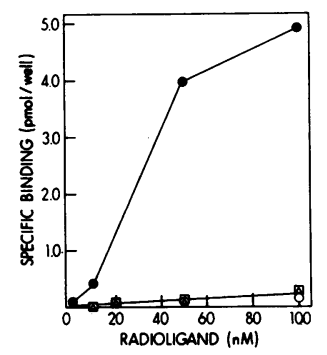

Figure 3. Binding of PEG-modified streptokinase to immunoglobulins at differing concentrations. Binding of radiolabeled streptokinase to immunoglobulin-coated wells was determined after a 6-h incubation with varying concentrations of ligand. ${ }^{125}$ I-streptokinase was unmodified (๑), modified by protocol A with PEG-2 (), PEG-4 ( $\Delta$ ), and PEG-5 (0) as described in the text. 


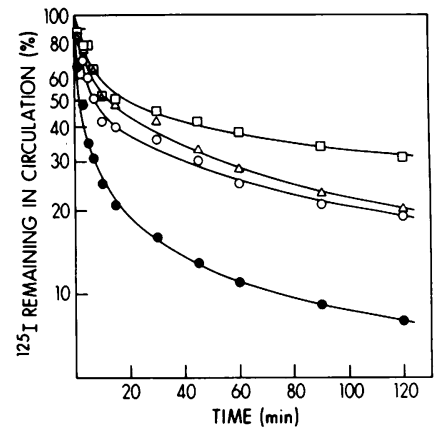

Figure 4. Plasma elimination of PEG-modified ${ }^{125}$ I-streptokinase. The percentage of the injected radiolabel remaining in the circulation was calculated relative to an initial time point drawn $5 \mathrm{~s}$ after injection. Streptokinase was unmodified (๑), or modified by protocol A with PEG-2 (口), PEG-4 ( $\triangle$ ), or PEG-5 $(0)$ as described in the text.

plasmin binds rapidly to $\alpha_{2}$-antiplasmin, and the complex is cleared by specific receptors in the liver $(7,25)$. Plasmin(ogen) as complexed with streptokinase reacts with $\alpha_{2} \mathrm{M}$ and is cleared from the circulation by a separate system of liver receptors. Fig. 5 shows clearance of preformed plasminogen activator consisting of ${ }^{125} \mathrm{I}$-plasmin and the streptokinase derivatives (protocol A). ${ }^{125}$ I-plasmin that was bound to unmodified streptokinase cleared rapidly, with a $50 \%$ elimination time of 3 min. ${ }^{125}$ I-plasmin that was incubated with PEG-5-streptokinase cleared significantly slower. The first $50 \%$ of the radioligand was eliminated within $13 \mathrm{~min}$; however, the clearance curve was at least biphasic and a significant component cleared very slowly. After $1 \mathrm{hr}, 37 \%$ of the radioactivity was still present in the circulation and the clearance had plateaued. These data suggest that PEG-5-streptokinase-plasminogen complex is less reactive with protease inhibitors in vivo when compared with unmodified plasminogen activator complex. ${ }^{125}$ I-plasmin in complex with PEG-2-streptokinase and PEG4-streptokinase was $50 \%$ eliminated in $7 \mathrm{~min}$ and 3-4 min, respectively.

Clearance competition experiments were performed in which ${ }^{125}$ I-plasmin-PEG-4-streptokinase was injected in the presence of a 600 -fold molar excess of $\alpha_{2} \mathrm{M}$-methylamine. Human $\alpha_{2} \mathrm{M}$-methylamine binds to cell membrane receptors accessible to the vascular compartment and interferes with the clearance of mouse $\alpha_{2} \mathrm{M}$-protease complexes that are formed simultaneously (26). Fig. 5 shows that the competing ligand decreased the rate of clearance of the radioiodinated plasmin. This result indicates that the modified plasminogen activator reacts with $\alpha_{2} \mathrm{M}$ in vivo, similarly to the unmodified streptokinase-plasmin(ogen) complex, albeit at a slower rate.

Plasma elimination of ${ }^{125}$ I-plasmin complexed with PEGstreptokinase prepared under different reaction conditions. Fig. 6 compares the clearances of the PEG-2- ${ }^{125}$ I-streptokinase derivatives prepared according to protocols A, B, and C. Both

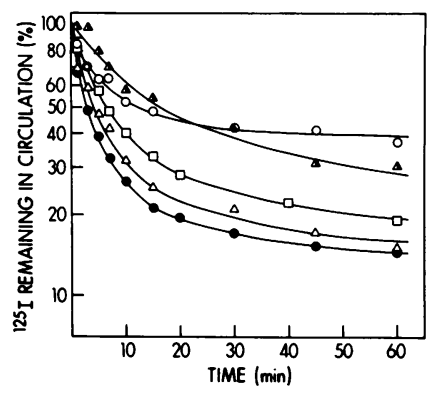

Figure 5. Plasma elimination of ${ }^{125}$ I-plasmin complexed with streptokinase. Activator complex was formed with radioiodinated human plasminogen and unmodified streptokinase $(\bullet)$, or streptokinase modified by protocol A with PEG-2 (), PEG-4 $(\Delta)$, or PEG-5 (0). The complex containing PEG-4streptokinase also was injected in the presence of a 600 -fold molar excess of $\alpha_{2} \mathrm{M}$-methylamine ( $\mathbf{\Delta})$.

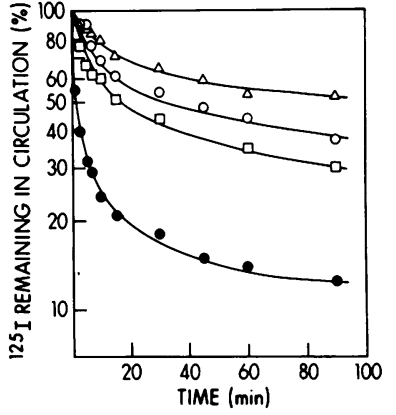

Figure 6. Plasma elimination of streptokinase modified with PEG2 under alternative reaction conditions. Clearance of native streptokinase (•) is compared with the clearance of streptokinase modified by protocol A ( $\square$ ), protocol B $(\Delta)$, and protocol C (O). sets of alternative reaction conditions (protocols B and C) yielded preparations that cleared slower than PEG-2-streptokinase prepared by protocol $\mathrm{A}$. These data most likely reflect more extensive derivatization of the streptokinase.

Activator complex was formed by incubating radioiodinated human plasminogen with the PEG-2-streptokinase derivatives from protocols B and C. These complexes cleared from the circulation at rates that were significantly prolonged when compared with ${ }^{125}$ I-plasmin activator complexes formed with PEG-2-streptokinase prepared according to protocol A (Fig. 7). These data suggest that the more extensively derivatized PEG-2-streptokinase preparations are less reactive with the plasma protease inhibitors.

\section{Discussion}

The efficacy of streptokinase in the treatment of thrombotic disorders is determined by several parameters including the ability of streptokinase to form an activator complex with plasminogen, the plasma concentration of antibody to streptokinase before streptokinase infusion, the ability of the streptokinase to react with antibody (antigenicity), the reactivity of the streptokinase-plasmin complex with $\alpha_{2} \mathrm{M}$, and the stimulation of the immune system by the infused streptokinase (immunogenicity). The rapid and strong immune response associated with intravenous streptokinase infusion frequently limits the duration of therapy (27). This has prompted attempts at chemical modification of streptokinase in order to produce derivatives that are nonantigenic (see reference 26 for review). Such derivatives could still be utilized in patients with high antibody titers. Koide et al. (10) derivatized streptokinase with PEG-5 that was activated by the cyanuric chloride method. These preparations did not react with antistreptokinase sera; however, the nonantigenic protein lost at least $67 \%$ of the original activity. The immunogenicity of this preparation was not studied.

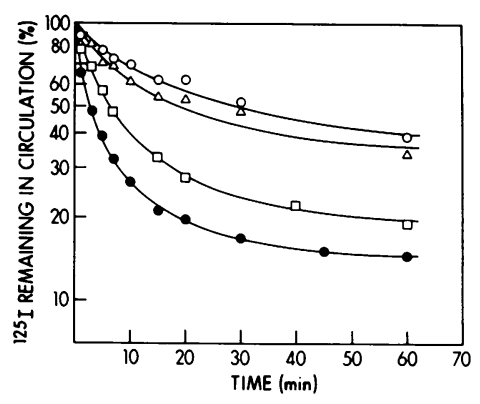

Figure 7. Plasma elimination of activator complex formed with ${ }^{125} \mathrm{I}$-plasminogen and streptokinase modified with PEG-2 under alternative reaction conditions. Activator complex contained ${ }^{125} \mathrm{I}$-plasmin and unmodified streptokinase $(\bullet)$ or streptokinase modified by protocol A ( $\square$ ), protocol B $(\Delta)$, or protocol C (O). 
A new method for activating PEG has recently been described (11). This method utilizes carbonyldiimidazole in the synthesis of an imidazole carbamate derivative of the hydroxyl group of PEG that can subsequently react with protein lysine residues (11). Coupling of the activated PEG to proteins is performed at $\mathrm{pH} 8.5$ and $4^{\circ} \mathrm{C}$, and the PEGprotein conjugates generally show little or no loss of functional activity (11). This is in marked contrast with results often obtained when other PEG coupling methods are utilized (28, 29). Proteins that are derivatized with carbonyldiimidazoleactivated PEG clear at significantly decreased rates independently of whether clearance results from interaction with carbohydrate receptors, receptors for specific sequences of amino acids or passive renal filtration (11).

In the present study, the carbonyldiimidazole technique was utilized to activate three different-sized PEGs that were then reacted with streptokinase. The derivatives demonstrated a number of altered properties that should be highly beneficial in the clinical use of the drug. Steady-state kinetic studies of activation showed decreased $k_{\text {cat }} / K_{\mathrm{m}}$ values for activator species containing derivatized as opposed to native streptokinase; this decrease was primarily an effect of decreased $k_{\text {cat }}$ values for the PEG derivatives. In that the plasma concentration of plasminogen is high $(\sim 2 \mu \mathrm{M})$ compared with activator complex, the modified streptokinase would still be expected to show considerable activity in the circulation despite the changes in the kinetic constants.

We also studied the plasmin activity obtained by incubating streptokinase or PEG-streptokinase with plasminogen as a function of time. In these studies PEG-derivatized streptokinase preparations yielded activities comparable with those of the native streptokinase. In view of the decreased catalytic efficiency of the modified activator preparations, these data were somewhat unexpected. However, the activity of PEG-streptokinase is influenced by factors other than initial rates of plasminogen activation. For instance, protection of the derivatized streptokinase from proteolytic attack by plasmin, in that PEG is coupled to lysine residues (11), may preserve streptokinase activity over time even though the initial rates are lower. This could explain the discrepancy between the steady-state kinetic data calculated from initial rates and the plasmin activity observed when PEG-streptokinase was incubated with plasminogen as compared to streptokinase. This discrepancy was particularly evident with PEG-5-streptokinase where kinetic constants could not be calculated. This question was addressed in experiments designed to detect degradation of streptokinase in activator complex.

Previous studies demonstrated that streptokinase is extensively degraded when in complex with rabbit plasminogen for 2-5 min (24). Human plasminogen complexed to streptokinase resulted in much less degradation under these conditions (8). However, when studied at $\mathbf{3 0} \mathrm{min}$, we found that streptokinase was extensively degraded when in complex with human plasminogen. Coupling of PEG-2 to the streptokinase significantly decreased degradation. These studies directly establish that PEG coupling to lysine residues protects the streptokinase from proteolytic attack. Therefore, the amount of plasmin activity observed in an incubation mixture containing PEGstreptokinase will depend not only on the kinetics of reaction, but also on the rate at which the streptokinase is subject to autodigestion. The decreased susceptibility of PEG-streptokinase to autodigestion is sufficient to offset the decreased catalytic efficiency of PEG-streptokinase (Fig. 1).
Moreover, as demonstrated in clearance studies discussed below, $\sim 40 \%$ of the injected PEG-2-streptokinase prepared by protocol B remains in the circulation after several hours. Under physiologic conditions, protection from autodegradation, therefore, is a significant factor in the potential ability of the streptokinase to function as a plasminogen activator in vivo, despite loss of catalytic efficiency.

Modification of streptokinase with PEG-2, PEG-4, or PEG5 also resulted in a dramatic decrease in antigenicity. Each derivative possessed only $\sim 5 \%$ of the reactivity demonstrated by unmodified streptokinase when incubated with antistreptokinase immunoglobulins bound to plastic microtiter wells. These data are consistent with the previous finding of Koide et al. (10) that PEG modification substantially decreases the antigenicity of streptokinase. It should be noted that no attempt was made in the present work to assess the immunogenicity of our preparations. In general, however, loss of antigenicity is accompanied by a significant decrease in immunogenicity $(28,29)$. This question will require further investigation.

Plasminogen activator complexes formed with PEG-streptokinase derivatives and radioiodinated human plasminogen cleared at a slower rate from the circulation of mice than did complex formed with unmodified streptokinase. It was previously demonstrated that catabolism of activator complex in this animal model reflects reaction with mouse $\alpha_{2} M$ (7). Evidence was also presented to suggest that the equivalent reaction may be important in determining the plasma half life of streptokinase in man. The murine clearance data presented here indicate that reaction of $\alpha_{2} \mathrm{M}$ with PEG-streptokinase activator complex in vivo occurs less readily. It is hypothesized that this decrease in reactivity might significantly lengthen the plasma survival of the thrombolytic agent in patients. Theiss et al. (30) recently presented data obtained from patients with deep vein thrombosis which support this hypothesis. These investigators measured $\alpha_{2}$-antiplasmin and $\alpha_{2} \mathrm{M}$ levels in patients treated with urokinase or streptokinase. Both fibrinolytic agents caused $\alpha_{2}$-antiplasmin levels to drop comparably to $\sim 20 \%$ of pretreatment level. A significant decrease in $\alpha_{2} M$ levels was detected only in streptokinase-treated patients $(55 \%$ of pretreatment level). $\alpha_{2}$-Antiplasmin is the primary inhibitor of free circulating plasmin, although $\alpha_{2} \mathrm{M}$ also will react with the protease when significant amounts are generated (31). The disproportionately large depletion of $\alpha_{2} \mathrm{M}$ in streptokinasetreated patients may be explained by reaction with activator complex as well as excess plasmin.

Many of the clearance curves presented in this manuscript were multiphasic or nonlinear. This type of curve would be expected if the extent of PEG derivatization was heterogeneous; however, other explanations are also possible including distribution of radioligand into the lymphatics and extracellular space and interaction with the endothelium. The possibility that antibody mediates this nonlinear clearance behavior seems unlikely in view of the poor reactivity of our PEG-streptokinase preparations with human antibodies.

By altering the conditions for reacting PEG-2 and streptokinase, derivatives were obtained that cleared from the circulation of mice at slower rates. This has been observed with other proteins and is considered evidence for more extensive modification (11). Because catabolism of the streptokinaseplasmin complex in mice involves transfer of the plasmin to $\alpha_{2} \mathbf{M}(7)$, it is possible that the larger PEG-5 adduct most effectively protects the plasmin bound to PEG-streptokinase 
from undergoing the transfer reaction. When the smaller PEG2 derivative is utilized, the extent of derivatization must be greater in order to impair the transfer reaction to a degree comparable to that seen with the PEG-5-streptokinase-plasmin complex.

In summary, derivatization of streptokinase with carbonyldiimidazole-activated PEG yields proteins that maintain good activator function in vitro and are protected from proteolytic degradation, but lose $90-95 \%$ of the capacity to bind to immunoglobulins. PEG-2-streptokinase derivatized with activated PEG-2 at a concentration of $80 \mathrm{mM}$ appears to possess the best functional properties inasmuch as it demonstrated only modest changes in steady-state kinetics constants, whereas incubation of this derivative with plasminogen resulted in plasmin activity comparable with that of native streptokinase over a 2-h period. This derivative also formed an activator species with plasminogen that had the longest in vivo survival. The activator complexes formed with the derivatized streptokinases may react more slowly with $\alpha_{2} \mathrm{M}$ in vivo than does native streptokinase. Thus, these preparations are free of the typical problems associated with the administration of streptokinase and have potential as improved therapeutic agents.

\section{Acknowledgment}

This work was supported by research grants HL-24066 and HL-31932 from the National Heart and Lung Institute.

\section{References}

1. DeRenzo, E. C., P. K. Sitteri, B. L. Hutchings, and P. H. Bell 1967. Preparation and certain properties of highly purified streptokinase. J. Biol. Chem. 242:533-542.

2. McClintock, D. K., and P. H. Bell. 1971. The mechanism of activation of human plasminogen by streptokinase. Biochem. Biophys. Res. Commun. 3:694-702.

3. Cederholm-Williams, S. A., F. DeCock, H. R. Lynen, and D. Collen. 1979. Kinetics of the reaction between streptokinase, plasmin, and $\alpha_{2}$-antiplasmin. Eur. J. Biochem. 100:125-132.

4. Gonzalez-Gronow, M., G. E. Siefring, and F. J. Castellino. 1978. Mechanism of activation of human plasminogen by the activator complex, streptokinase-plasmin. J. Biol. Chem. 253:1090-1094.

5. Porter, J. M., and S. H. Goodnight, Jr. 1977. The clinical use of fibrinolytic agents. Am. J. Surg. 134:217-221.

6. Stack, R. S., H. R. Phillips, D. S. Grierson, V. S. Behar, Y. Kong, R. H. Peter, J. L. Swain, and J. C. Greenfield. 1982. Functional improvement of jeopardized myocardium following intracoronary streptokinase infusion in acute myocardial infarction. J. Clin. Invest. 70:412-423.

7. Gonias, S. L., M. Einarsson, and S. V. Pizzo. 1982. Catabolic pathways for streptokinase, plasmin, and streptokinase activator complex in mice. J. Clin. Invest. 70:412-423.

8. Brockway, W. J., and F. J. Castellino. 1974. A characterization of native streptokinase and altered streptokinase isolated from a human plasminogen activator complex. Biochemistry. 13:2063-2070.

9. Spoettl, F., and R. Kaiser. 1974. Rapid detection and quantitation of precipitating streptokinase antibodies. Thromb. Diath. Haemorrh. 32:608-616.

10. Koide, A., S. Suzuki, and S. Kobayashi. 1982. Preparation of polyethylene glycol-modified streptokinase with disappearance of binding ability towards anti-serum and retention of activity. FEBS (Fed. Eur. Biochem. Soc.) Lett. 143:73-76.

11. Beauchamp, C. O., S. L. Gonias, D. P. Menapace, and S. V. Pizzo. 1983. A new procedure for the synthesis of polyethylene glycolprotein adducts: effects on function, receptor recognition, and clearance of superoxide dismutase, lactoferrin, and $\alpha_{2}$-macroglobulin. Anal. Biochem. 131:25-33.

12. Deutsch, D. G., and E. T. Mertz. 1970. Plasminogen: purification from human plasma by affinity chromatography. Science (Wash. DC). 170-1095-1096.

13. Brockway, W. J., and F. J. Castellino. 1972. Measurement of the binding of antifibrinolytic amino acids to various plasminogens. Arch. Biochem. Biophys. 151:194-199.

14. Castellino, F. J., J. M. Sodetz, W. J. Brockway, and G. E. Siefring, Jr. 1977. Enzymes of clot lysis: streptokinase. Methods Enzymol. 45:244-257.

15. Imber, M. J., and S. V. Pizzo. 1981. Clearance and binding of two electrophoretic "fast" forms of human $\alpha_{2}$-macroglobulin. J. Biol. Chem. 256:8134-8139.

16. Einarsson, M., B. Skoog, B. Forsberg, and R. Einarsson. 1979. Characterization of highly purified native streptokinase and altered streptokinase after alkaline treatment. Biochim. Biophys. Acta. 568:1929.

17. Sjoholm, I., B. Wiman, and P. Wallen. 1973. Studies on the conformational change of plasminogen induced during activation to plasmin and by 6-amino-hexanoic acid. Eur. J. Biochem. 39:471-479.

18. Hall, P. K., and R. C. Roberts. 1978. Physical and chemical properties of human $\alpha_{2}$-macroglobulin. Biochem. J. 171:27-38.

19. David, G. S., and R. A. Reisfeld. 1974. Protein iodination with solid state lactoperoxidase. Biochemistry. 13:1014-1021.

20. Wohl, R. C., L. Summaria, L. Arzadon, and K. C. Robbins 1978. Steady state kinetic of activation of human and bovine plasminogens by streptokinase and its equimolar complexes with various activated forms of human plasminogen. J. Biol. Chem. 253:14021407.

21. Wohl, R. C., L. Summaria, and K. C. Robbins. 1980. Kinetics of activation of human plasminogen by different activator species at pH 7.4 and $37^{\circ}$ C. J. Biol. Chem. 255:2005-2013.

22. Gonias, S. L., and S. V. Pizzo. 1983. Conformation and protease binding activity of binary and ternary human $\alpha_{2}$-macroglobulinprotease complexes. J. Biol. Chem. 258:14682-14685.

23. Polson, A., G. M. Potgeiter, J. F. Largier, G. E. F. Mears, and F. J. Joubert. 1964. The fractionation of protein mixtures by linear polymers of high molecular weight. Biochim. Biophys. Acta. 82:463475.

24. Siefring, G. E., and F. J. Castellino. 1976. Interaction of streptokinase with plasminogen. Isolation and characterization of a streptokinase degradation product. J. Biol. Chem. 251:3913-3920.

25. Gonias, S. L., H. E. Fuchs, and S. V. Pizzo. 1982. A unique pathway for the plasma elimination of $\alpha_{2}$-antiplasmin-protease complexes in mice. Thromb. Haemostasis. 48:208-210.

26. Gonias, S. L., A. E. Balber, W. J. Hubbard, and S. V. Pizzo. 1983. Ligand binding, conformational change and plasma elimination of human, mouse, and rat $\alpha$-macroglobulin proteinase inhibitors. Biochem. J. 209:99-105.

27. Kakkar, V. V., A. A. Sasahara, and D. P. Thomas. 1981. Treatment of venous thromboembolism. In Haemostasis and Thrombosis, Vol. 39. A. L. Bloom and D. P. Thomas, editors. ChurchillLivingstone, Inc., New York. 684-711.

28. Pyatak, P. S., A. Abuchowski, and F. F. Davis. 1980. Preparation of a polyethylene glycol: superoxide dismutase adduct, and an examination of its blood circulation life and anti-inflammatory activity. Res. Commun. Chem. Pathol. Pharmacol. 29:113-271.

29. Abuchowski, A., T. van Es, N. C. Palczuk, J. R. McCoy, and F. F. Davis. 1979. Treatment of L5178Y tumor-bearing BDF1 mice with a nonimmunogenic L-glutaminase-L-asparaginase. Cancer Treat. Rep. 63:1127-1132.

30. Theiss, W., F. Asbeck, A. Kriessmann, G. Truebestein, K. Knoch, C. A. M. de Swart, G. A. Marbet, and J. C. W. Van De Loo. 1983. Inhibitor levels during treatment of deep vein thrombosis. Throm. Haemastasis. 50:664-668.

31. Collen, D. On the regulation and control of fibrinolysis. 1980. Thromb. Haemostasis. 43:77-89. 